\title{
Demonstration of oestrogenic control of H-type-1 carbohydrate antigen in the murine endometrial epithelium by use of ICI 182,780
}

\author{
I. M. Illingworth and S. J. Kimber* \\ School of Biological Sciences, 3.239 Stopford Building, University of Manchester, Oxford Road, Manchester M13 9PT, UK
}

\begin{abstract}
The carbohydrate H-type- 1 antigen has been implicated in attachment of the murine blastocyst to the endometrial epithelium. Monoclonal antibody 667/9E9 was used to investigate the steroidal dependency of expression of this antigen in the murine endometrial epithelium using intact or ovariectomized mice treated with oestrogen or the pure anti-oestrogen, ICI 182,780. The effects of this anti-oestrogen were also investigated in the endometrial epithelium from intact rats. In both ovariectomized, oestrogen-supplemented and intact mice after treatment with ICI 182,780, staining with monoclonal antibody 667/9E9 was abolished in the luminal epithelium on both the apical and lateral cell surfaces, whereas basal staining remained. Glandular staining in mice was not affected in the same manner. In intact rats, where H-type-1 antigen expression has been reported to be predominantly controlled by progesterone, the antioestrogen had little effect, in accordance with previous reports.
\end{abstract}

\section{Introduction}

The adult mammalian uterus undergoes cyclic differentiation in all species (Leavitt, 1989), although the time scale and details differ. Pregnancy interrupts this cycle and triggers a series of changes directed towards the survival and growth of the early embryo and its subsequent implantation. Specific pre- and peri-implantation changes in the uterus are a pre-requisite for successful implantation, allowing placental and fetal development. It is well established that these changes are under the control of ovarian steroids (Finn and Martin, 1970; Psychoyos, 1973). For instance, as well as stimulating DNA synthesis, oestrogen affects endometrial epithelial cell morphology (Ljungkvist, 1971) and, in combination with progesterone, influences cell architecture and glycoprotein expression at the apical epithelial plasma membrane (Murphy and Rogers, 1981; Kimber and Lindenberg, 1990; Denker, 1993; Kimber et al., 1994; Murphy and Shaw, 1994). Expression of a number of uterine proteins is stimulated by ovarian oestrogen (Pentecost and Teng, 1987; Brown et al., 1990) which selectively induces the secretion of specific proteins (Sundstrom et al., 1989; Glasser and Mulholland, 1993). The expression of some carbohydrate antigens on the endometrial epithelium shows steroiddependent changes during the rodent oestrous cycle, during early pregnancy and in ovariectomized animals treated with oestrogen or progesterone, or both hormones (Kimber $\mathrm{et}$ al., 1988, 1994, 1995; Kimber and Lindenberg, 1990). One of these, the H-type- 1 antigen, is not present after implantation in mice and is transiently undetectable in rats (Kimber $e t a l$., 1988, 1995). In mice, addition of the H-type-1 antigen

Revised manuscript received 2.5 January 1999 (displayed on a pentasaccharide) to the culture medium of endometrial luminal epithelial monolayers inhibits blastocyst attachment to the epithelial cells (Lindenberg et al 1988; Kimber et al 1994; Kimber and Sidhu 1997). A monoclonal antibody that recognizes the H-type-1 antigen (mAb 667/9E9) inhibited attachment similarly, but this effect could not be obtained with other related sugars or antibodies. Furthermore, a receptor for this antigen has been detected on the blastocyst, appearing at the time of hatching, specifically on the abembryonic trophectoderm (Lindenberg et al., 1990; Yamagata and Yamazaki, 1991). This finding indicates that the luminal epithelial H-type-1 carbohydrate plays a role in attachment of the blastocyst. Steroidal control of the H-type- 1 antigen appears to differ among species: in mice, the H-type-1 antigen is stimulated by oestrogen (Kimber and Lindenberg, 1990; White and Kimber, 1994) whereas, in rats, progesterone and oestrogen together appear to stimulate maximal expression (Kimber et al., 1995).

This study investigated the effects of pure anti-oestrogen ICI $182,780, \quad 7 \alpha[9-(4,4,5,5,5-$ pentafluoro-pentylsulphinyl) nonyl]oestra-1,3,5(10)-triene-3,17 $\beta$-diol on the expression of the H-type- 1 antigen in mice and rats. It was undertaken to establish more clearly the oestrogen dependency of this carbohydrate antigen in mice, and whether the antigen does not depend on oestrogen in the rat. Monoclonal antibody $667 / 9 \mathrm{E} 9$ was used and the antibody batch used in this study has been shown to have specificity for the H-type- 1 antigen in the endometrium (Kimber and Lindenberg, 1990, A. Cook and S. J. Kimber, unpublished). 182,780 has a relatively high binding affinity for uterine oestrogen receptors (ER): $90 \%$ of that of oestrogen (Wakeling et al., 1991). Hence, it is thought to exert its anti-oestrogenic effects by competing with oestrogen for binding to its receptor. Unlike compounds such as tamoxifen, which have both oestrogenic and anti- 
Table 1. Regimen for hormone treatment of mice and rats

\begin{tabular}{|c|c|c|c|c|c|c|c|c|c|c|c|}
\hline \multirow[b]{2}{*}{ Group } & \multirow[b]{2}{*}{ Surgical procedure } & \multicolumn{10}{|c|}{$\begin{array}{c}\text { Day } \\
\text { (treatment begins } 12-15 \text { days after ovariectomy) }\end{array}$} \\
\hline & & 1 & 2 & 3 & 4 & 5 & 6 & 7 & 8 & 9 & 10 \\
\hline Ov Control & Ovariectomized & EB & EB & EB & - & - & $\mathrm{CO}$ & $\mathrm{CO}$ & $\mathrm{CO}$ & $\mathrm{CO}$ & $\mathrm{K}$ \\
\hline Ov E & Ovariectomized & $\mathrm{EB}$ & EB & EB & - & - & $\mathrm{E}$ & E & $\mathrm{E}$ & $\mathrm{E}$ & $\mathrm{K}$ \\
\hline Ov 182 & Ovariectomized & $\mathrm{EB}$ & EB & $\mathrm{EB}$ & - & - & 182 & 182 & 182 & 182 & K \\
\hline Control & None & - & - & - & - & - & $\mathrm{CO}$ & $\mathrm{CO}$ & $\mathrm{CO}$ & $\mathrm{CO}$ & $\mathrm{K}$ \\
\hline 182 & None & - & - & - & - & - & 182 & 182 & 182 & 182 & $\mathrm{~K}$ \\
\hline 182 low & None & - & - & - & - & - & 182 low & 182 low & 182 low & 182 low & K \\
\hline
\end{tabular}

CO: corn oil vehicle; EB: priming dose of 100 ng oestradiol 3-benzoate; E: 100 ng oestradiol; $182: 1$ mg ICI 182,780 (mice), 2 mg ICI 182,780 (rats); $\mathrm{T}^{\prime}: 1 \mathrm{mg} 182,780$ + 100 ng oestradiol; T²: $250 \mu$ g 182,780 + 100 ng oestradiol; 182 low: $250 \mu$ ICI 182,780 (mice), 500 mg ICI 182,780 (rats); Ov: ovariectomized; K: killed.

All treatments were carried out on mice, but treatments Control, 182 and 182 low were also carried out on intact rats.

oestrogenic effects (Ross and Whitehead, 1995), 182,780 acts as a specific anti-oestrogen in vivo in rodents, without exhibiting any oestrogenic activity. For instance, it blocks the uterotrophic action of tamoxifen as well as that of oestradiol (Wakeling et al., 1991; Wakeling, 1995). It is similarly effective in primates and humans (Dukes et al., 1992, 1993; Thomas et al., 1994).

The present results show that staining with $\mathrm{mAb} 667 / 9 \mathrm{E} 9$ on apical and lateral cell surfaces in the murine endometrial luminal epithelium is abolished totally by 182,780 . In contrast, basal staining remains, as reported after ovariectomy without steroid replacement or with progesterone supplementation (Kimber et al., 1994). Expression of a major oestrogen-inducible endometrial epithelial glycoprotein, lactoferrin (Pentecost and Teng, 1987; McMaster et al., 1992), is also depleted after treatment with 182,780 , confirming the anti-oestrogenic action of 182,780 in the present study.

\section{Materials and Methods}

\section{Mice and rats}

Six week old female MF1 mice and Sprague-Dawley rats were obtained from Harlan (Bicester) and maintained under a $12 \mathrm{~h}$ light: $12 \mathrm{~h}$ dark cycle with water and food provided ad libitum.

\section{Ovariectomy, hormone and 182,780 supplementation}

Female mice were bilaterally ovariectomized under Hypnorm (0.313 mg fentanyl $\mathrm{ml}^{-1}, 10 \mathrm{mg}$ fluanisone $\mathrm{ml}^{-1}$ ): midazolam (1:1) anaesthetic. This was administered i.p. at $10 \mathrm{mg} \mathrm{ml}^{-1}$. The animals were left for 12-15 days to recover and for endogenous ovarian hormone concentrations to subside. All hormone injections were given at 16:00 h in $0.1 \mathrm{ml}$ corn oil as described by White and Kimber (1994) and Kimber et al. (1995). The mice were primed with three s.c. injections of $100 \mathrm{ng}$ oestradiol 3-benzoate $(1,3,5,[10]-$ oestratriene-3,17 $\beta$-diol 3-benzoate) (Sigma, Poole). The animals were left for 2 days and then injected according to the procedures detailed (Table 1). In addition, nonovariectomized mice and rats of comparable age were injected using the control, 182 and 182 low regimens (Table 1). These animals were not given priming injections.

Compound ICI 182,780 (7 $\alpha$ [9-(4,4,5,5,5-pentafluoropenty]sulphinyl)nonyl]oestra-1,3,5(10)-triene-3,17 $\beta$-diol) (Zeneca, Macclesfield) was dissolved in ethanol and made up at 2.5 or $10 \mathrm{mg} \mathrm{ml}^{-1}$ in corn oil and administered in the same way as the hormones (Wakeling et al., 1991). On the basis of previous results, doses were equivalent to 10 or $40 \mathrm{mg} \mathrm{kg}^{-1}$ body weight for mice, or 2.5 or $10 \mathrm{mg} \mathrm{kg}^{-1}$ body weight for rats (Wakeling et al., 1991; A. E. Wakeling, personal communication). Injections were carried out on days $6,7,8$ and 9 as follows: ovariectomized mice, four daily injections of corn oil alone (Ov control); ovariectomized mice, four daily injections of $100 \mathrm{ng}$ oestradiol (Ov E); ovariectomized mice, four daily injections of $1 \mathrm{mg}$ 182,780 (Ov 182); ovariectomized mice, four daily injections of $1 \mathrm{mg} \mathrm{182,780+100} \mathrm{ng} \mathrm{oestradiol} \mathrm{(Ov} \mathrm{182(1)}$ $+\mathrm{E})$; ovariectomized mice, four daily injections of $250 \mu \mathrm{g}$ $182,780+100 \mathrm{ng}$ oestradiol (Ov 182(0.25) $+\mathrm{E}$ ). For the nonovariectomized animals, the following treatments were also carried out: mice and rats: four daily injections of corn oil

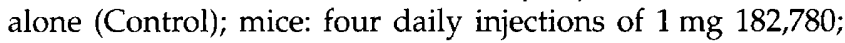
rats: four daily injections of $2 \mathrm{mg} \mathrm{182,780} \mathrm{(182);} \mathrm{mice:} \mathrm{four}$ daily injections of $250 \mu \mathrm{g} 182,780$; rats: four daily injections of

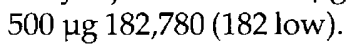

In each of the ovariectomized groups, mice and rats were killed by cervical dislocation $22-24 \mathrm{~h}$ after the final injection.

\section{Tissue processing and immunocytochemistry}

Animals were killed between 14:00 and 15:00 $\mathrm{h}$ and the uterine horns were dissected and cut into three pieces. The pieces were immersed in OCT embedding compound (Raymond Lamb, Eastbourne) and snap-frozen in liquid nitrogen. Frozen tissue was stored at $-80^{\circ} \mathrm{C}$ until required for 
Table 2. Summary of staining using monoclonal antibody against the H-type-1 antigen on tissue from intact and ovariectomized mice

\begin{tabular}{|c|c|c|c|c|c|c|c|c|c|c|c|}
\hline \multirow[b]{2}{*}{ Group } & \multicolumn{5}{|c|}{ Luminal epithelium } & \multicolumn{5}{|c|}{ Distal glandular epithelium } & \multirow[b]{2}{*}{ Str } \\
\hline & Ap & Bas & Lat & Cyt & Sec & Ap & Bas & Lat & Cyt & $\mathrm{Sec}$ & \\
\hline Control & +++ & +++ & +++ & ++ & + & +++ & +++ & ++ & +++ & + & - \\
\hline 182 & - & ++ & - & - & - & $+/++$ & + & + & ++ & + & - \\
\hline 182 low & - & ++ & - & + & - & $+/++$ & + & + & ++ & + & - \\
\hline Ov Control & - & ++ & - & - & - & + & + & + & ++ & + & - \\
\hline $\mathrm{OVE}$ & +++ & ++ & + & ++ & + & ++ & ++ & + & ++ & + & - \\
\hline Ov 182 & - & ++ & - & - & - & ++ & + & + & ++ & + & - \\
\hline Ov $182(1)+E$ & - & ++ & - & - & - & + & + & + & ++ & + & - \\
\hline Ov $182(0.25)+E$ & - & ++ & - & - & - & + & + & + & ++ & + & - \\
\hline
\end{tabular}

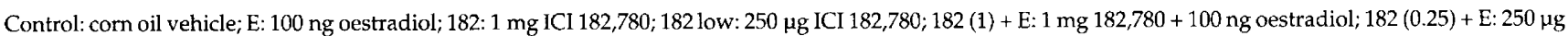
$182,780+100 \mathrm{ng}$ oestradiol.

First three rows, intact animals. Ov: ovariectomized mice; Ap: apical; Bas: basal; Lat: lateral; Cyt: cytoplasmic; Sec: secretions; Str: stroma.

sectioning. Two transverse $7 \mu \mathrm{m}$ sections of uterus from areas at least $140 \mu \mathrm{m}$ apart were taken from each animal for immunocytochemical analysis. Sections were fixed in acetone (BDH Laboratory Supplies, Poole) at $4^{\circ} \mathrm{C}$ for $10 \mathrm{~min}$ and used immediately or stored at $-80^{\circ} \mathrm{C}$ for up to 2 weeks. Double-layer immunofluorescence was carried out as described by Kimber et al. (1988) and White and Kimber (1994). Sections taken from three mice were examined for each steroid or steroid-anti-oestrogen treatment. These were stained with the primary antibody, mouse monoclonal antibody (mAb) 667/9E9 (IgM; MonoCarb AB, formerly Biocarb $\mathrm{AB}$, Lund), which recognizes the H-type 1

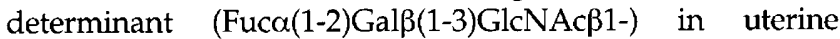
epithelium. Some later batches of this antibody do have some affinity for the H-type-2 antigen but these were not used in this study. As a control for the anti-oestrogenic affect of 182,780 , antiserum to mouse lactoferrin (gift of C. Teng, NIH, NC) was also used. This protein is strongly oestrogendependent. The antiserum was raised in rabbits against a murine $70 \mathrm{kDa}$ uterine oestrogen-inducible protein (McMaster et al., 1992). A fluorescein isothiocyanate (FITC)-conjugated goat anti-mouse or goat anti-rabbit antibody (Sigma) was used for the second layer. For each secondary antibody, a negative immunological control was carried out using normal goat serum (Sigma) in place of primary antibody. Mouse MAb 650/4B5 (IgM; MonoCarb AB, formerly Biocarb AB), which recognizes glycophorin- $\mathrm{N}$, was also used as negative control for $667 / 9 \mathrm{E} 9$. Complete series that included each experimental group were immunostained on the same day. Each experimental series was immunostained using identical procedures. Antibody binding was assessed using a Leitz Dialux epifluorescence microscope. Staining was scored blind and photographed using TMAX 400 pro film (Kodak).

\section{Results}

\section{H-type-1 antigen}

Intact mice. The staining patterns detected using monoclonal antibody against $\mathrm{H}$-type- 1 antigens on tissue from intact mice are summarized (Table 2). Sections of uterus from corn oil-treated mice (Fig. 1a) showed a staining pattern similar to that observed by White and Kimber (1994) for nonpregnant mice at most stages of the cycle apart from prooestrus. All aspects of the luminal and glandular epithelial cell surfaces were strongly stained and there was also moderate cytoplasmic staining. In mice treated with both $1 \mathrm{mg}$ and $250 \mu \mathrm{g} 182,780$ (Fig. 1b,c), there was a total absence of apical and lateral cell surface staining in the luminal epithelium with anti-H-type-1 antibody. A small amount of apical cytoplasmic staining was sometimes observed at the lower dose. Basal staining remained high after treatment at either concentration. In contrast, the glandular epithelium of 182,780-treated mice was stained on apical, basal and lateral surfaces and in the cytoplasm, although this was diminished in comparison with the corn oil-treated controls. Staining of glands proximal to the lumen was reduced to a greater degree than that seen in more distal glands. Significant staining of uterine luminal secretions was only seen in the controls given corn oil (Fig. 1a). However, a moderate amount of glandular luminal staining was seen after all treatments. Negative controls using either normal goat serum or $\mathrm{mAb} 650 / 4 \mathrm{~B} 5$ showed no staining on any surface (data not shown). 182,780 substantially reduced staining for the oestrogen-dependent protein, lactoferrin, confirming its anti-oestrogenic properties (data not shown).

Ovariectomized mice. The staining patterns detected using monoclonal antibody against $\mathrm{H}$-type-1 antigens on tissue from ovariectomized mice are summarized (Table 2). As established by Kimber and Lindenberg (1990) and Kimber et al. (1994), after ovariectomy and corn oil treatment, sections of uterus showed relatively little staining (Fig. 2a). Exceptions were the basal region of the luminal epithelium and a small amount of staining on all surfaces and the cytoplasm of the epithelia in the glands. Treatment with 182,780 alone (Fig. 2c) gave a staining pattern that was indistinguishable from that with corn oil, except for marginally increased apical staining in the glands. In animals treated with oestrogen, the H-type-1 antigen was strongly expressed on the apical surface of the luminal epithelium and moderately expressed on the lateral and basal surfaces and cytoplasm (Fig. 2b). Glands were stained on all cell 

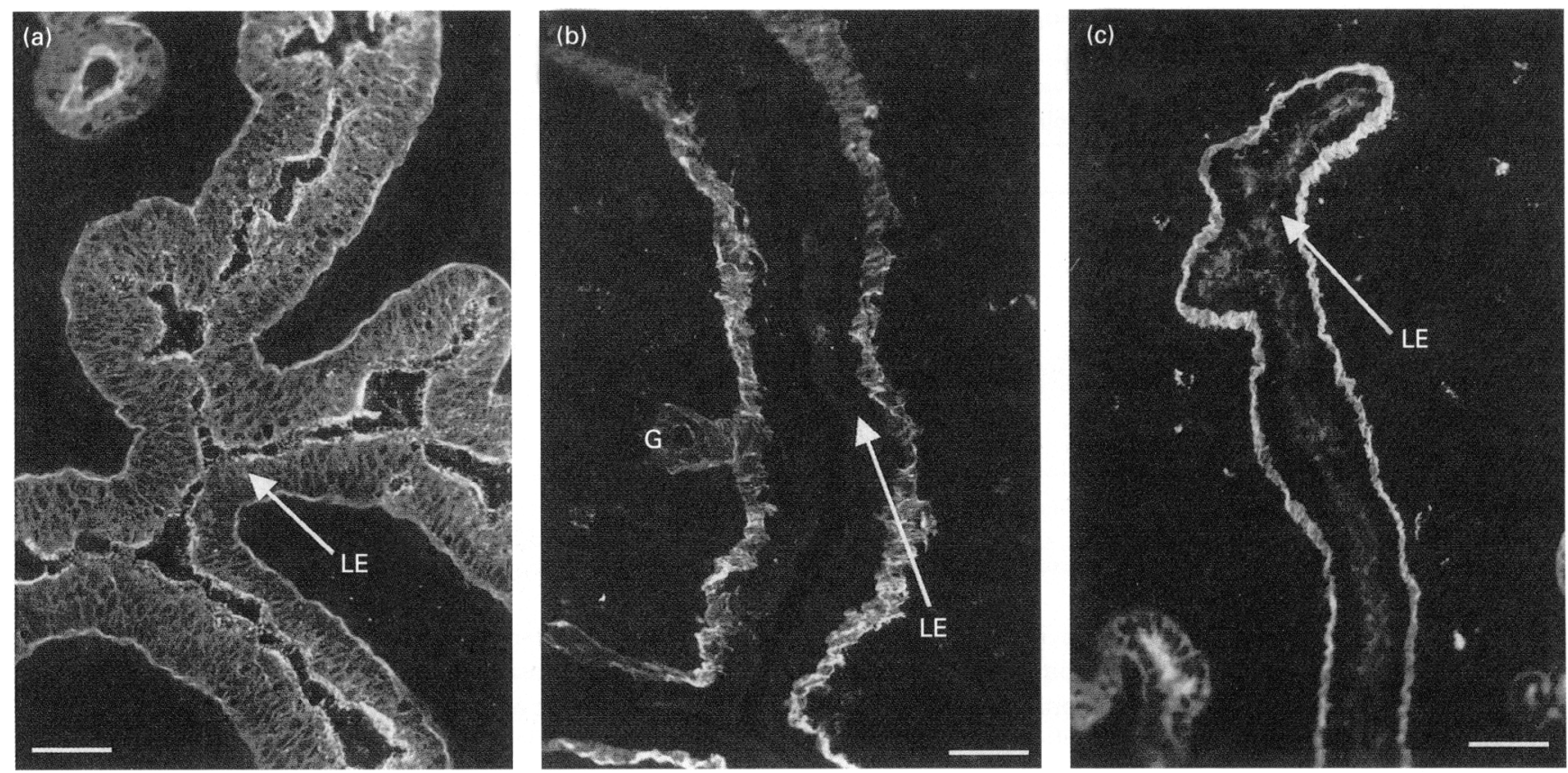

Fig. 1. Staining of the murine endometrium from intact animals using monoclonal antibody against the $\mathrm{H}$-type-1 antigen after the treatment indicated. (a) Corn oil only (control). All cell surfaces of the luminal and glandular epithelium show strong staining with moderate cytoplasmic staining also visible. (b) $1 \mathrm{mg}$ ICI 182,780 (182) (c) $250 \mu \mathrm{g}$ ICI 182,780 (182 low). Both anti-oestrogen treatments show a lack of apical and lateral cell surface staining in the lumen, although basal staining remains high. After the lower dose of 182,780 , there is slight cytoplasmic staining. Glandular staining is generally low on all cell surfaces, but glands distal to the lumen show some moderate apical surface staining (c). LE: luminal epithelium; G: gland. Scale bars represent $50 \mathrm{um}$.

surfaces and in the cytoplasm. After treatment with oestrogen plus 182,780, all staining seen in oestrogen-treated animals on the luminal epithelium was abolished, except for the small amount of basal staining (Fig. 2d). This pattern was identical for both doses of 182,780 . The glandular epithelium was stained on all surfaces in a similar manner to that seen with corn oil. No staining of uterine luminal secretions was seen except in animals given oestrogen, in which staining was frequently high (Fig. 2b). Glandular secretions were stained after all treatments. Serum or antibody negativecontrols showed no staining on any surface (data not shown). In ovariectomized mice, endometrial epithelial staining for the control antigen, lactoferrin, was only seen after oestrogen treatment and was abolished by 182,780, again confirming its anti-oestrogenic properties (data not shown).

Intact rats. The staining patterns detected using monoclonal antibody against H-type-1 antigens on tissue from intact rats are summarized (Table 3). Sections of uterus from female rats treated with either $500 \mu \mathrm{g}$ or $2 \mathrm{mg} 182,780$ showed strong staining of all surfaces of the cells and the cytoplasm in luminal and glandular epithelium (Fig. 3b,c). This staining intensity was higher than that seen in control rats given corn oil (Fig. 3a), in which the staining of the lateral cell surfaces and the cytoplasm of the luminal epithelium was enhanced compared with controls. Normal goat serum or antibody negative-controls again showed no staining on any surface (data not shown).

\section{Discussion}

The anti-oestrogen 182,780 was used to investigate the control of $\mathrm{H}$-type- 1 carbohydrate antigen expression in the murine endometrial epithelium. Previous work indicated that this antigen is stimulated by oestrogen and repressed by progesterone in mice (Kimber and Lindenberg, 1990; Kimber 't al., 1994; White and Kimber, 1994). In rats, the pattern of expression on the endometrial epithelium is superficially similar to that in mice. In early pregnancy, maximum luminal epithelial expression occurs before implantation. However, after ovariectomy followed by ovarian steroid supplementation, immunofluorescence indicated that the antigen is stimulated by progesterone and maximally expressed after oestrogen together with progesterone (Kimber ot al., 1995). Furthermore, after implantation, the antigen is depressed only transiently from the rat luminal epithelium, while it is absent for several days in that of mice. Expression is also retained in ovariectomized rats, but not in mice, treated with steroids to produce a refractory epithelium.

The present results in mice show that 182,780 can abolish luminal epithelial reactivity with monoclonal antibody against $H$-type- 1 antigens, except at the basal surfaces. In contrast, staining of the murine glandular epithelium is only slightly affected by 182,780 . This finding is in accordance with the observation that the expression of the antigen, on all but the basal surface of the luminal epithelium, is strongly oestrogen-dependent. In contrast, on the glandular epithelium, expression of the antigen is only weakly stimulated by 

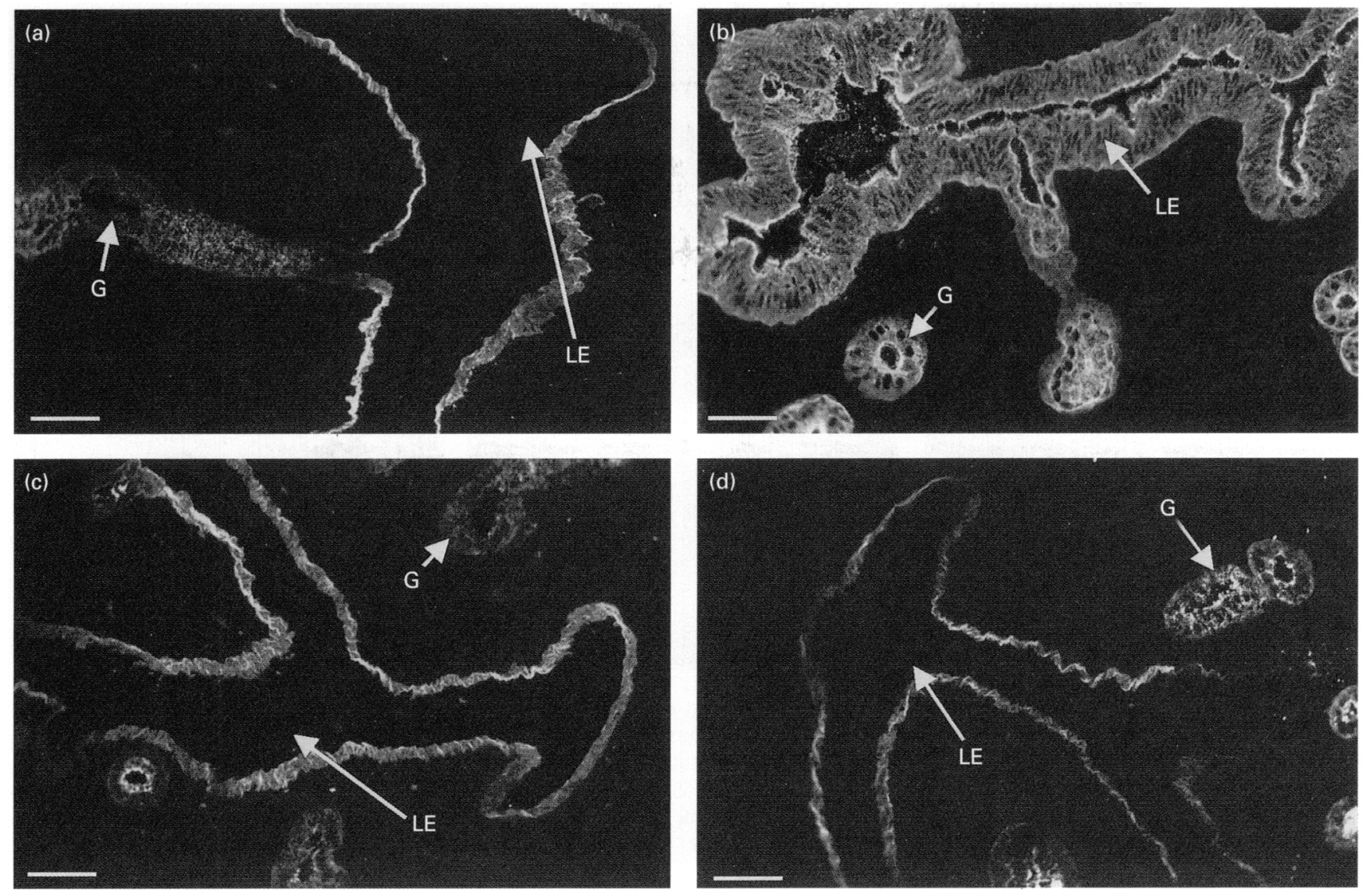

Fig. 2. Staining of the murine endometrium using monoclonal antibody against the H-type-1 antigen after ovariectomy and the treatment indicated. (a) Corn oil only (Ov control). Little or no staining is visible on any aspect of the luminal epithelium, with the exception of the basal cell surface. Glandular cell surfaces and cytoplasm are negative adjacent to the lumen, whereas distal to lumen, they show moderate staining. (b) $100 \mathrm{ng}$ oestradiol $(\mathrm{O}, \mathrm{E}$ ). All cell surfaces and cytoplasmic regions show strong staining on both the glandular and luminal epithelium, with marginally greater staining on the apical surfaces of luminal epithelium and some glands. (c) $1 \mathrm{mgr}$ ICI 182,780 (O) 182). (d) $100 \mathrm{ng}$ oestradiol and $250 \mu \mathrm{g}$ ICI $182,780(\mathrm{O} \cdot 182(0.25)+$ E). Treatment with 182,780 , with or without oestrogen, results in a pattern of staining very similar to that seen in mice treated with corn oil alone. LE: luminal epithelium; G: gland. Scale bars represent 50 um.

Table 3. Summary of staining using monoclonal antibody against the $\mathrm{H}$-type- 1 antigen on tissue from intact rats

\begin{tabular}{|c|c|c|c|c|c|c|c|c|c|c|c|}
\hline \multirow[b]{2}{*}{ Group } & \multicolumn{5}{|c|}{ Luminal } & \multicolumn{5}{|c|}{ Glandular } & \multirow[b]{2}{*}{ Str } \\
\hline & Ap & Bas & Lat & Cyt & Sec & Ap & Bas & Lat & Cyt & $\mathrm{Sec}$ & \\
\hline Control & ++ & ++ & + & + & + & +++ & ++ & ++ & ++ & + & - \\
\hline 182 & +++ & +++ & +++ & +++ & ++ & +++ & ++ & ++ & +++ & + & - \\
\hline $182 \mathrm{low}$ & +++ & +++ & +++ & +++ & ++ & +++ & ++ & ++ & +++ & + & - \\
\hline
\end{tabular}

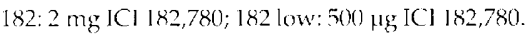

Ap: apical; bas: basal; I.at: lateral; Cyt: cytoplasmic; Sce secretions; Str: stroma.

oestrogen (Kimber et al., 1994). There are several possible explanations for these differences. The H-type-1 epitope is known to be carried on at least one major glycoprotein and one glycolipid as well as several minor components in the luminal epithelium (Kimber et al., 1994; Kimber and Sidhu, 1997). Not all molecules carrying the H-type- 1 antigen may be oestrogen-dependent; one or more molecules that are not steroid-dependent may be expressed at the basal surface, perhaps in the basement membrane, or in glands. In addition, the turnover of the H-type- 1 antigen, or its carrier molecule, may be much lower in glandular epithelium or at the basal luminal epithelial surface.

In intact rats, 182,780 had much less effect on staining for the H-type-1 antigen. If there was an effect, there was marginally greater staining in compound-treated rats. In these animals, progesterone will be present and is in accordance with previous findings that indicated that $\mathrm{H}$ type-1 antigen expression in rat endometrial epithelium is primarily dependent on progesterone stimulation (Kimber et al., 1995). However, maximum expression was found in 

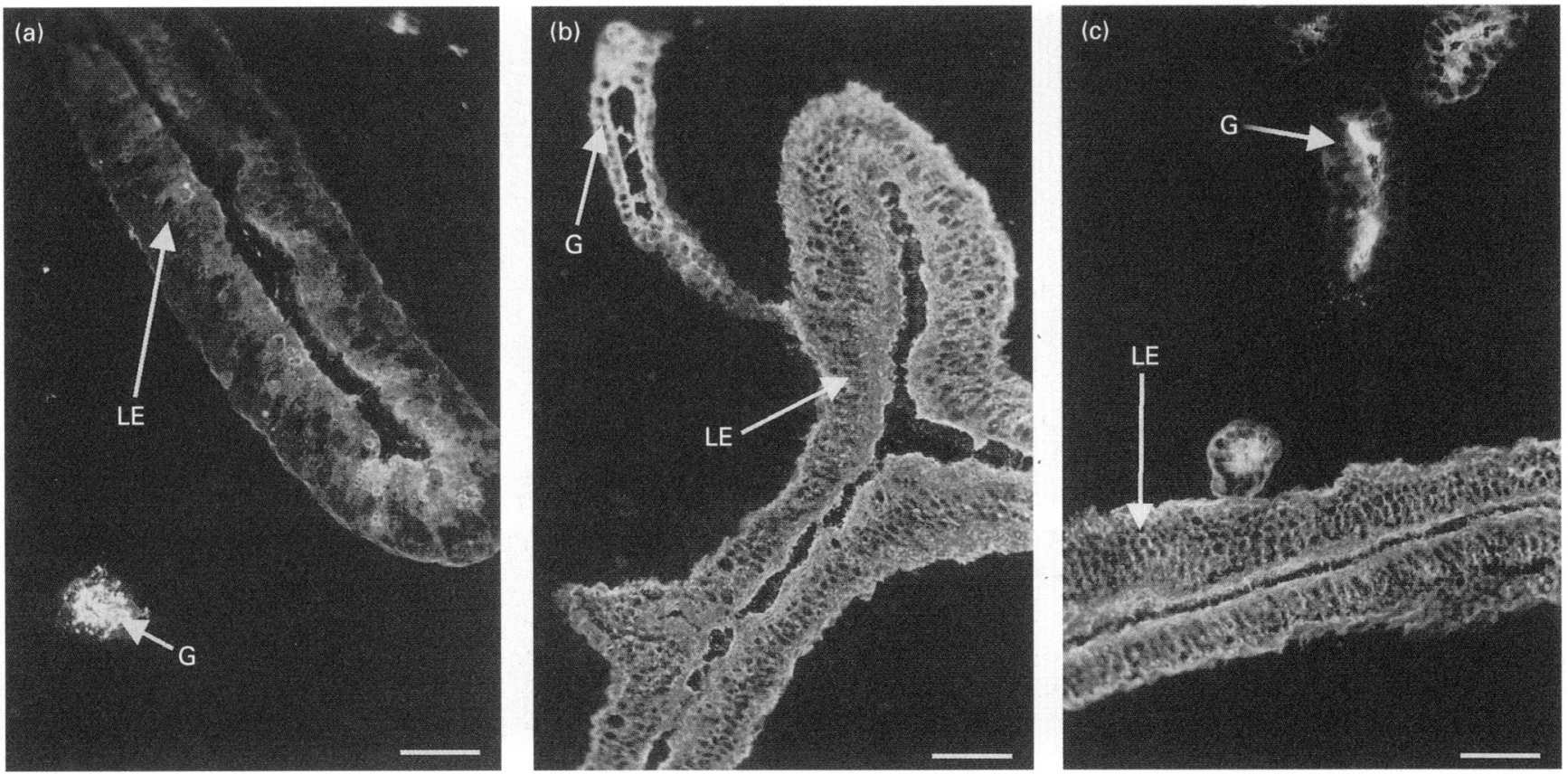

Fig. 3. Staining of the endometrium from intact rats using monoclonal antibody against the H-type- 1 antigen after the treatment indicated. (a) Corn oil only (control). Moderate staining is visible on the apical and basal cell surfaces and apical cytoplasm of the luminal epithelium, with a small amount of staining also visible on the lateral cell surfaces. Glandular staining is strong on the apical cell surfaces and cytoplasm. (b) $2 \mathrm{mg}$ ICI 182,780 (182). (c) $500 \mu \mathrm{g}$ ICI 182,780 (182 low). Treatments with 182,780 at either dose result in strong staining on all luminal cell surfaces and cytoplasm. Glandular staining is also strong, particularly on the apical cell surface, with moderate staining visible on all other cell surfaces. LE: luminal epithelium; G: gland. Scale bars represent $50 \mu \mathrm{m}$.

ovariectomized rats after giving progesterone followed by progesterone plus a nidatory dose of oestrogen (Kimber $e t$ al., 1995). The present results with 182,780 indicate that oestrogen concentrations in nonpregnant rats may antagonize H-type-1 antigen expression. The involvement of other hormones or factors in the control of this epitope cannot be ruled out. These may act either in parallel to ovarian steroids, or as secondary factors resulting from ovarian steroidreceptor activation.

Considering that the precise steroidal regulation of uterine luminal epithelial H-type- 1 antigen in rats and mice is clearly different, the changes in expression in pre- and periimplantational phases of pregnancy are remarkably similar. The major difference is the lack of downregulation after implantation in rats (see above). The appearance of the $\mathrm{mAb}$ bound fluorescence is also different, being markedly punctate in murine epithelium. This finding may reflect different carrier molecules in the two species. Such different carrier macromolecules are likely also to differ in turnover. In mice, the antigen is carried on one major $110 \mathrm{kDa}$ glycoprotein and also on a neutral glycolipid (Kimber $e^{2}$ al., 1994; Kimber and Sidhu, 1997; P. Paulsson, unpublished). The molecule(s) carrying this carbohydrate epitope in the rat has not been characterized. The differences between rats and mice may also reflect differences in steroid sensitivity due to receptor availability and differences in steroid interaction with cytokines and growth factors in the endometrium (McLachlan ef al., 1991; Sharkey, 1995; Tabibzadeh and Babaknia, 1995).
In murine endometrium, the major control of expression of the H-type-1 antigen occurs at stimulation of $\alpha 1-2$ fucosyltransferase activity by oestrogen and repression by progesterone (White and Kimber, 1994) and this regulation appears to occur at the expression of the transferase mRNA (Kimber and Sidhu 1997; Sidhu and Kimber, 1999). Whether the epitope is similarly controlled in rats has not been examined.

As expected, 182,780 greatly reduced the expression of the oestrogen-inducible protein, lactoferrin, in the endometrial epithelium of intact and ovariectomized mice. This finding confirmed the oestrogenic stimulation of the molecule in murine endometrial epithelium and the anti-oestrogenic effects of $182,780.182,780$ has been demonstrated to reverse the effects of oestrogen in a number of ovarian steroidresponsive cell types from different species (Wakeling, 1995), including human breast tumours and tumour cell lines (Osborne et al., 1995). Not only does 182,780 suppress oestrogen-dependent cell proliferation and antigen expression (Blin et al., 1995; Osborne et al., 1995) but it is also able to mimic apoptotic cell death promoted by steroid withdrawal in pituitary tumour cells (Newton, 1995). It would be valuable to investigate the effect of this compound on cell death in the endometrium. The uterus undergoes cyclical changes in both epithelial and stromal apoptosis apparently relating to changes in ovarian steroid concentrations (Finn and Publicover, 1981; Pollard et al., 1987; Tabibzadeh et al., 1994; Koh et al., 1995).

It is generally accepted that the anti-oestrogenic action of 
compounds such as tamoxifen, ICI 164,384 and 182,780 stems from their binding to the oestrogen receptor, thereby preventing oestrogen stimulation. Non-receptor binding sites are known for other anti-oestrogens and it has been demonstrated that 182,780 binds with high affinity to a site in breast cancer cells different from the oestrogen receptor or other anti-oestrogen binding sites (Parisot et al., 1995). Whatever the binding site is for 182,780 in the endometrium, the present results indicate that its major effect is to abolish the expression of an oestrogen-dependent carbohydrate epitope.

The authors are most grateful to A. Wakeling for invaluable advice, to $C$. Teng for the gift of antiserum to murine lactoferrin and to WellBeing for financial support.

\section{References}

Blin C, L'Horset F, Leclerc T, Lambert M, Colnot S, Thomasset $M$ and Perret M (1995) Contrasting effects of tamoxifen and 182,780 on estrogen-induced calbindin-D 9k gene expression in the uterus and in primary culture of myometrial cells Journal of Steroid Biochemistry and Molecular Biology 55 1-7

Brown EO, Sundstrom SA, Komm BS, Yi Z, Teuscher C and Lyttle CR (1990) Progesterone regulation of estradiol-induced rat uterine secretary protein, complement $\mathrm{C} 3$ Biology of Reproduction 42 713-719

Denker HW (1993) Implantation: a cell biological paradox Joumal of Experimental Zoology 266 541-558

Dukes M, Miller D, Wakeling AE and Waterton JC (1992) Antiuterotrophic effects of a pure antioestrogen, ICI 182,780: magnetic resonance imaging of the uterus in ovariectomized monkeys Journal of Endocrinology 135 239-247

Dukes M, Waterton JC and Wakeling AE (1993) Antiuterotrophic effects of the pure antioestrogen, ICI 182,780 in adult female monkeys (Macaca nemestrina): quantitative magnetic resonance imaging Journal of Endocrinology 138 203-209

Finn CA and Martin L (1970) The role of the oestrogen secreted before oestrus in the preparation of the uterus for implantation in the mouse Journal of Endocrinology $47431-438$

Finn CA and Publicover M (1981) Hormonal control of cell death in the luminal epithelium of the mouse uterus Journal of Endocrinology 91 335-340

Glasser SR and Mulholland J (1993) Receptivity is a polarity dependant structural function of hormonally regulated uterine epithelial cells Microscopical Research Techniques 25 106-120

Kimber SJ and Lindenberg S (1990) Hormonal control of carbohydrate determinants involved in implantation Journal of Reproduction and Fertility 89 13-21

Kimber SJ and Sidhu SS (1997) Control of expression of the H-type-1 histoblood group antigen in the murine endometrial epithelium and its role in blastocyst adhesion Human Reproduction 12 58-64

Kimber SJ, Lindenberg S and Lundblad A (1988) Distribution of some GalB1$3(4) \mathrm{GlcNAc}$-related carbohydrate antigens on the mouse uterine epithelium in relation to the peri-implantation period Journal of Reproductive Immunology 12 297-313

Kimber SJ, White S, Cook A and Illingworth IM (1994) The initiation of implantation: parallels between attachment of the embryo and neutrophilendothelial interaction? In Gametes and Embryo Quality pp 171-198 Ed. L Mastrioianni, Jr. Proceedings of the 4th Organon Round Table Conference, Thessaloniki, Geece. Parthenon Publications, Carnforth

Kimber SJ, Hllingworth IM and Glasser SR (1995) Expression of carbohydrate antigens in the rat uterus during early pregnancy and after ovariectomy and steroid replacement Journal of Reproduction and Fertility 103 75-87

Koh EAT, Illingworth PJ, Duncan WC and Critchley HOD (1995) Immunolocalization of bcl-2 protein in human endometrium in the menstrual cycle and simulated early pregnancy Human Reproduction 10 $1557-1562$

Leavitt WW (1989) Cell biology of the endometrium In Biology of the Uterus Edn 2 pp 131-173 Eds RM Wynn and WP Jollie. Plenum Publishing Co., New York Lindenberg S, Sundberg K, Kimber SJ and Lundblad A (1988) The milk oligosaccharide lacto- $\mathrm{N}$-fucopentose I inhibits implantation of mouse blastocysts on endometrial monolayers Journal of Reproduction and Fertility 83 149-158

Lindenberg S, Kimber SJ and Kallin E (1990) Carbohydrate binding properties of mouse embryos Journal of Reproduction and Fertility 89 431-439

Ljungkvist I (1971) Attachment reaction of the rat uterine luminal epithelium II. The effect of progesterone on the morphology of the uterine glands and the luminal epithelium of the spayed virgin rat Acta Societies of Medicine Uppsala 76 110-126

McLachlan JA, Nelson KG, Takahashi T, Bossert NL, Newbold RR and Korach KS (1991) Do growth factors mediate estrogen action in the uterus? New Biology of Steroid Hormones Serono Symposium 74 337-344

McMaster MT, Teng CT, Dey SK and Andrews GK (1992) Lactoferrin in the mouse uterus: analyses of the preimplantation period and regulation by ovarian steroids Molecular Endocrinology 6 101-111

Murphy CR and Rogers AW (1981) Effects of ovarian hormones in the rat uterus III. The surface carbohydrates at the apex of the luminal epithelium Cellular Biophysics 3 305-320

Murphy CR and Shaw TJ (1994) Plasma membrane transformation: a common response of the uterine cells during the peri-implantation period Cell Biology International 18 1115-1128

Newton CJ (1995) Estrogen receptor blockade by the pure antiestrogen, ZM 182780 , induces death of pituitary tumour cells Journal of Steroid Biochemistry and Molecular Biology 55 327-336

Osborne CK, Coronado-Heinsohn EB, Hilsenbeck SG, McCue BL, Wakeling AE McClelland RA, Manning DL and Nicholson RI (1995) Comparison of the effects of a pure steroidal antiestrogen with those of tamoxifen in a model of human breast cancer Iournal of the National Cancer Institute 87 746-750

Parisot JP, Hu XF, Sutherland RL, Wakeling A, Zalcberg JR and DeLuise M (1995) The pure antiestrogen ICI 182,780 binds to a high-affinity site distinct from the estrogen receptor International Journal of Cancer 62 480-484

Pentecost BT and Teng CT (1987) Lactotransferrin is the major estrogen inducible protein of mouse uterine secretions Journal of Biological Chemistry 26210134-10139

Pollard JW, Pacey J, Cheng SVY and Jordan EG (1987) Estrogens and cell death in murine uterine luminal epithelium Cell and Tissue Research 249 $533-540$

Psychoyos A (1973) Hormonal control of ovimplantation Vitamins and Hormones 31 201-256

Ross D and Whitehead M (1995) Hormonal manipulation and gynaecological cancer: the tamoxifen dilemma Current Opinion in Obstetrics and Gynecology $763-68$

Sharkey A (1995) Cytokines and embryo / endometrial interactions Reproductive Medicine Review 4 87-100

Sidhu SS and Kimber SJ (1999) Hormonal control of the H-type $\alpha(1-$ 2)fucosyltransferase messenger ribonucleic acid in the mouse uterus Biology of Reproduction 60 147-157

Sundstrom, SA, Komim BS, Ponce-de-Leon H, Yi Z, Teuscher C and Lyttle CR (1989) Estrogen regulation of tissue-specific expression of complement C3 Journal of Biological Chemistry 264 16941-16947

Tabibzadeh S and Babaknia A (1995) The signals and molecular pathways involved in implantation, a symbiotic interaction between blastocyst and endometrium involving adhesion and tissue invasion Human Reproduction 101579-1602

Tabibzadeh S, Kong QF, Satyaswaroop PG, Zupi E, Marconi D, Romanini C and Kapur S (1994) Distinct regional and menstrual cycle dependant distribution of apoptosis in human endometrium. Potental regulatory role of $T$ cells and TNF- $\alpha$ Endocrine Journal 2 87-95

Thomas EJ, Walton PL, Thomas NM and Dowsett M (1994) The effects of ICI 182,780 , a pure anti-oestrogen, on the hypothalamic-pituitary-gonadal axis and on endometrial proliferation in pre-menopausal women Human Reproduction 9 1991-1996

Wakeling AE (1995) Use of pure antioestrogens to elucidate the mode of action of oestrogens Biochemical Pharmacology 49 1545-1549

Wakeling AE, Dukes $\mathbf{M}$ and Bowler J (1991) A potent specific pure antiestrogen with clinical potential Cancer Research 51 3867-3873

White $\mathbf{S}$ and Kimber SJ (1994) Changes in $\alpha(1-2)$ fucosyltransferase activity in the murine endometrial epithelium during the estrous cycle, early pregnancy and after ovariectomy and hormone replacement Biology of Reproduction 50 73-81

Yamagata T and Yamazaki K (1991) Implanting mouse embryos stain with LNF-1 bearing fluorescent probe at their mural trophectoderm side Biochemical Research Communications 181 1004-1009 